\title{
RESEARCH ACTIVITY USING MOLECULAR BEAM AND LASER TECHNIQUES: A PROGRESS REPORT
}

\author{
J. CASTAÑO ${ }^{\mathrm{a}}$, S. SKOWRONEK ${ }^{\mathrm{a}}$, M. GARAY ${ }^{\mathrm{a}}$, \\ B. BESCOS ${ }^{\mathrm{a}}$, V. ZAPATA ${ }^{\mathrm{a}}$, J. M. OREA ${ }^{\mathrm{a}}$, \\ A. LAPLAZA ${ }^{a}$, G. TARDAJOS ${ }^{\mathrm{a}}$, R. PEREIRA ${ }^{\mathrm{a}}$, C. RINALDI ${ }^{\mathrm{a}}$ \\ and A. GONZÁLEZ UREÑA ${ }^{\mathrm{a}, \mathrm{b}, *}$ \\ ${ }^{a}$ Instituto Pluridisciplinar Unidad de Láseres y \\ Haces Moleculares Juan XXIII-1 ${ }^{\circ}$, \\ Universidad Complutense 28040-Madrid, Spain; \\ ${ }^{\mathrm{b}}$ Departamento de Química Física Facultad de Química \\ Universidad Complutense de Madrid 28040-Madrid, Spain
}

(Received 5 June 1996)

\begin{abstract}
We shall briefly describe the main research areas, now in progress in our molecular beam and laser group. The current activity includes our traditional molecular beam work as well as other experiments carried out in the new labs of our Institute. Essentially we present here the current progress on Crossed-beam and Beam-gas Chemilumine scence, Laser-induced Beam Surface Reaction, Laser Analytical Chemistry, Laser-initiated Reactions Studies by Chemiluminescence and Laser-induced Fluorescence, Spectroscopy and Structure of van der Waals molecules. For each section recent results are presented. Due to the basic scope of the present progress report the emphasis is made on the new experimental developments as well as on the capabilities of both basic and applied research techniques now operative in our group.
\end{abstract}

Keywords: Molecular beams; lasers; reaction dynamics; chemiluminescence

\section{CROSSED-BEAM AND BEAM-GAS CHEMILUMINESCENCE SPECTROSCOPY [1-16]}

In this line of research molecular collisions are studied using both crossed-beam and beam-gas arrangements. An experimental description

*To whom correspondence should be addressed. 
is omitted here for brevity. The interested reader is referred to Ref. 4, for a detailed presentation of the techniques. Much of the experimental work recently undertaken using these two techniques has been dedicated to the study of the dynamics of excited reactions [5], typically using alkaline-earth atoms. The study of the following type of reactions:

$$
\mathrm{Ca}^{*}+\mathrm{HX}(\mathrm{X}=\mathrm{Cl}, \mathrm{Br}) \rightarrow \mathrm{CaX}^{*}+\mathrm{H}
$$

has been carried out under single collision conditions. Since the calcium atom can be readily prepared in two metastable states, namely $\mathrm{Ca}\left({ }^{3} \mathrm{P}_{J}\right)$ and $\mathrm{Ca}\left({ }^{1} \mathrm{D}_{2}\right)$, the total and differential cross-sections can be measured for the reaction of the two distinct electronic states. Figure 1 shows a schematic view of the crossed-beam molecular apparatus. More details can be found in Ref. 15 in which electronically excited

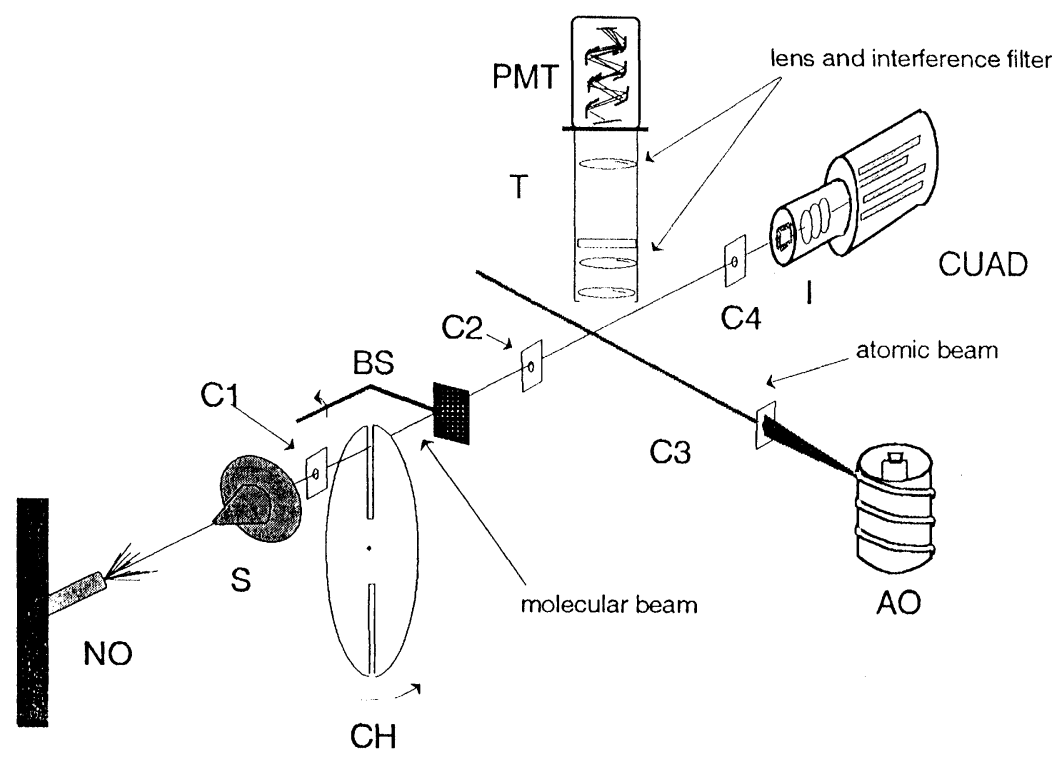

FIGURE 1 Schematic view of our crossed-beam molecular beam apparatus. An excited calcium atom collides with a supersonic reagent $(\mathrm{HCl}$, for example) leading to electronically excited products whose fluorescence is collected and resolved. NO: nozzle oven, S: skimmer, CH: modulating disc, BS: beam stop, AO: atomic oven, T: telescope, PMT: photomultiplier tube, I: ionizer, CUAD: cuadrupole mass spectrometer and $\mathbf{C n}$ : beam colimators. See Ref. 4 for more details. 
calcium atoms in a beam collide with molecules in a supersonic beam (typically, $\mathrm{HBr}, \mathrm{HCl}, \mathrm{N}_{2} \mathrm{O}$, etc). By using a pulsed calcium beam any spontaneous product fluorescence can be detected in coincidence with the reagent pulse. This allows us to measure high resolution excitation functions like the one shown in Figure 2. The collision energy dependence of the chemiluminescent reaction cross-section as well as the polarization of the chemiluminescence were studied to gain insight into the dynamics and stereodynamics of these prototype heavy + heavy-light reactions. Significant features now under study include the

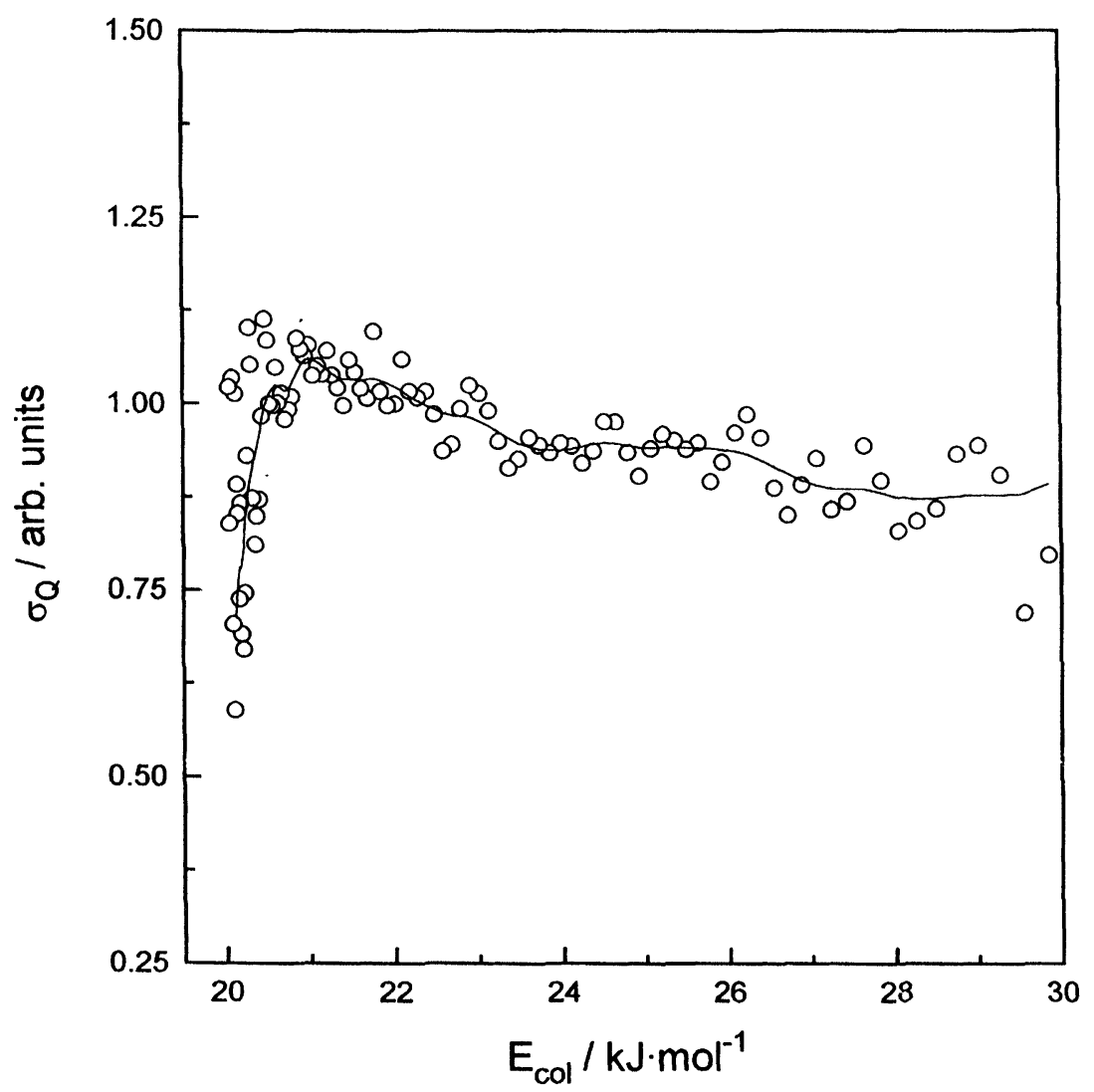

FIGURE 2 Collision energy dependence of the cross-section for the $\mathrm{Ca}\left({ }^{1} \mathrm{D}\right)+\mathrm{HBr}$ $\rightarrow \mathrm{CaBr}\left(\mathrm{A}^{2} \Pi\right)+\mathrm{H}$ reaction. Notice the energy threshold around $\mathrm{E}_{T}=0.2 \mathrm{eV}$ even though the reaction is exoergic in $\Delta \mathrm{D}^{0}{ }_{0}=46.50 \mathrm{~kJ} \cdot \mathrm{mol}^{-1}$. 
possibility of quantal effects, which could manifest themselves as resonances in their excitation functions and a correlation between the L-L' vectors (i.e. between the reagent-product orbital angular momenta). As can be seen in Figure 2 an energy threshold results around $E_{T}-0.2 \mathrm{eV}$ for the chemiluminiscent $\mathrm{Ca}\left({ }^{1} \mathrm{D}_{2}\right)+\mathrm{HBr} \rightarrow \mathrm{CaBr}\left(\mathrm{A}^{2} \Pi\right)$ $+\mathrm{H}$ reaction. The appearance of such a threshold in spite of a reaction exothermicity of $\Delta \mathrm{D}^{0}{ }_{0}=46.50 \mathrm{~kJ} \cdot \mathrm{mol}^{-1}$ is a matter now under study. A more complete discussion can be found in Ref. 4 and 16.

Figure 3 shows the excitation function for the $\mathrm{Ca}\left({ }^{1} \mathrm{D}_{2}\right)+\mathrm{HCl} \rightarrow$ $\mathrm{CaCl}(\mathrm{A})+\mathrm{H}$ reaction (top Fig.) together with different model calculations using a harpooning model based on succesive and independent crossings through the relevant covalent and ionic potentials of the displayed potential energy surfaces [12]. The manifold of these crossings is shown in Figure 4. The major significance of these results obtained with the harpooning dynamics is that the observed translational features of the $\mathrm{Ca}\left({ }^{1} \mathrm{D}_{2}\right)+\mathrm{HCl} \rightarrow \mathrm{CaCl}+\mathrm{H}$ chemiluminiscent reaction can be explained by the combination of two reaction channels. One is open at all energies above $\sim 80 \mathrm{meV}$ and the other is operative only above $\sim 200 \mathrm{meV}$. Whereas the former deals with crossings number 1 and 2, see Figure 4, the latter is clearly associated to the inner crossing between the covalent $\mathrm{Ca}\left({ }^{1} \mathrm{P}\right)+\mathrm{HCl}$ and ionic $\mathrm{Ca}^{+}\left({ }^{2} \mathrm{D}\right)+\mathrm{HCl}^{-}$potentials, and it has been shown [12] that is responsible for the rising of $\sigma_{R}$, the reaction cross-section, and its maximum at the collision energy, $E_{T} \sim 290 \mathrm{meV}$.

The onset of significant threshold for these highly exothermic reactions is of some interest by itself since it not only provides relevant data to understand the dynamics of excited reactions, but it also furnishes a good example on that the symmetry and topology of the excited potential, and not only the total energy, is one of the key factors controlling the reactivity of such excited species.

The product chemiluminescence spectrum as well as the polarization of the emission can be measured when the beam-gas arrangement is used. A schematic view of the set-up is shown in Figure 5. A detailed spectrum of the CaI* $(\mathrm{A}, \mathrm{B})$ formed in the $\mathrm{Ca}\left({ }^{1} \mathrm{D}\right)+\mathrm{CH}_{3} \mathrm{I} \rightarrow$ $\mathrm{CaI}\left(\mathrm{A}^{2} \Pi, \mathrm{B}^{2} \Sigma\right)+\mathrm{CH}_{3}$ reaction is displayed in Figure 6. Notice the presence of both $\mathrm{A}$ and $\mathrm{B}$ states as well as the splitting of the ${ }^{2} \Pi$ state. As mentioned above, looking at the polarization of the emission provides insight into the stereodynamics of the elementary chemical 


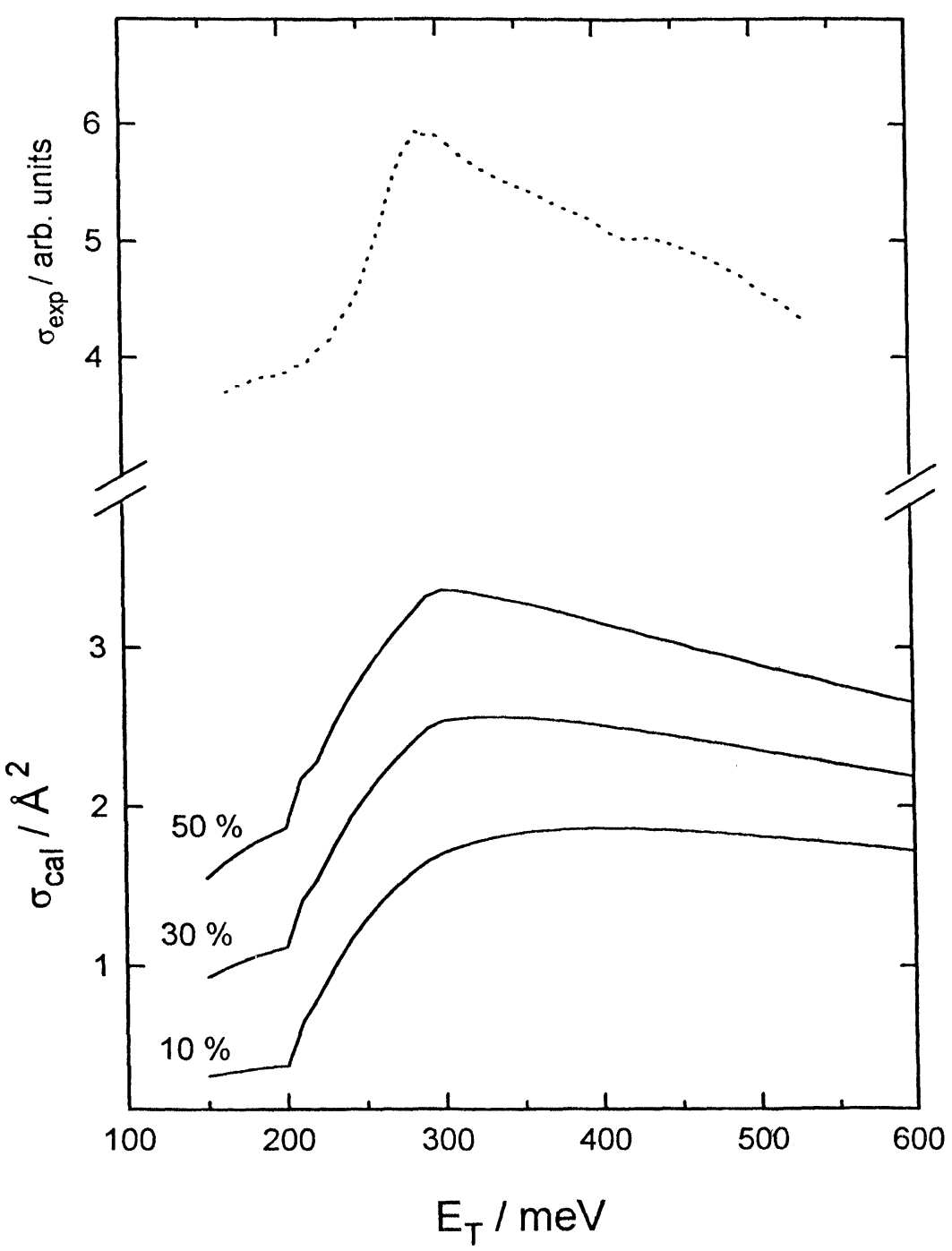

FIGURE 3 Three sample calculations of the cross-section for production of $\mathrm{CaCl}$ $\left(\mathrm{A},{ }^{2} \Pi\right)$ corresponding to three different relative contributions due to the channel which involves crossing 2 (see Fig. 4). For a better illustration and comparison the experimental $\sigma_{R}\left(\mathrm{E}_{T}\right)$, is also displayed at the top of the Figure. Adapted from Ref. 12 . 


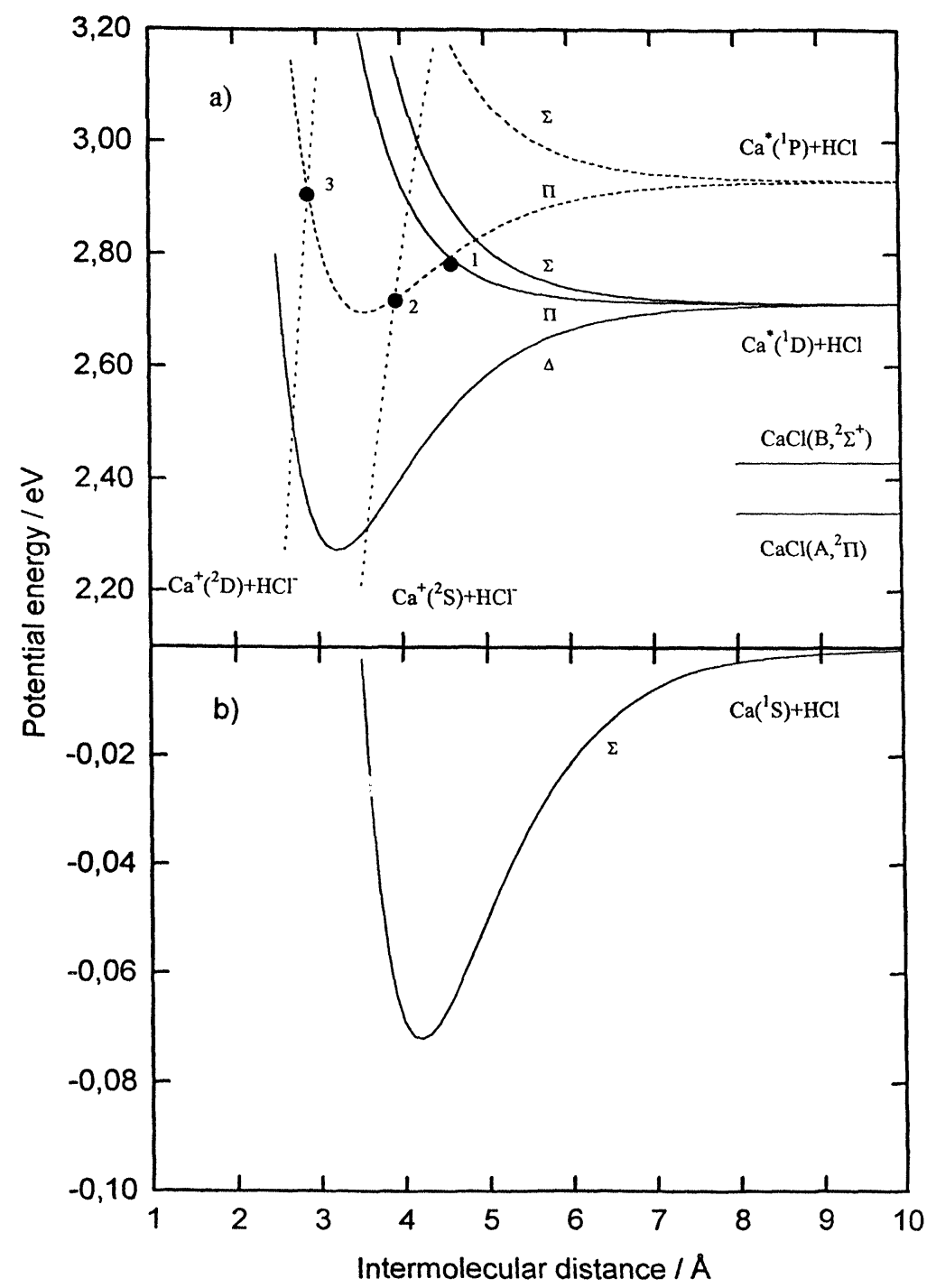

FIGURE 4 Plots of potential energy curves relevant for the description of the entrance channels for the reactions of excited calcium atoms and $\mathrm{HCl}$, as estimated neglecting dependence from $\mathrm{HCl}$ orientation (this allows the $\Sigma, \Pi, \Delta$ labelings at long range, see text). Ionic curves are also shown as dotted lines and features of crossings as used in Eqs. 12,13 are: $\mathrm{R}_{1}=4.58, \mathrm{R}_{2}=3.92, \mathrm{R}_{3}=2.89 \AA, \mathrm{E}_{1}=84, \mathrm{E}_{2}=8 \mathrm{meV}, \mathrm{E}_{3}=201 \mathrm{meV}$, $\Delta_{1}=40, \Delta_{2}=964$ and $\Delta_{3}=2862 \mathrm{meV}$. $\AA^{-1}$. The lower curve, corres- ponding to the ground state, is discussed in the text. Adapted from Ref. 12. 

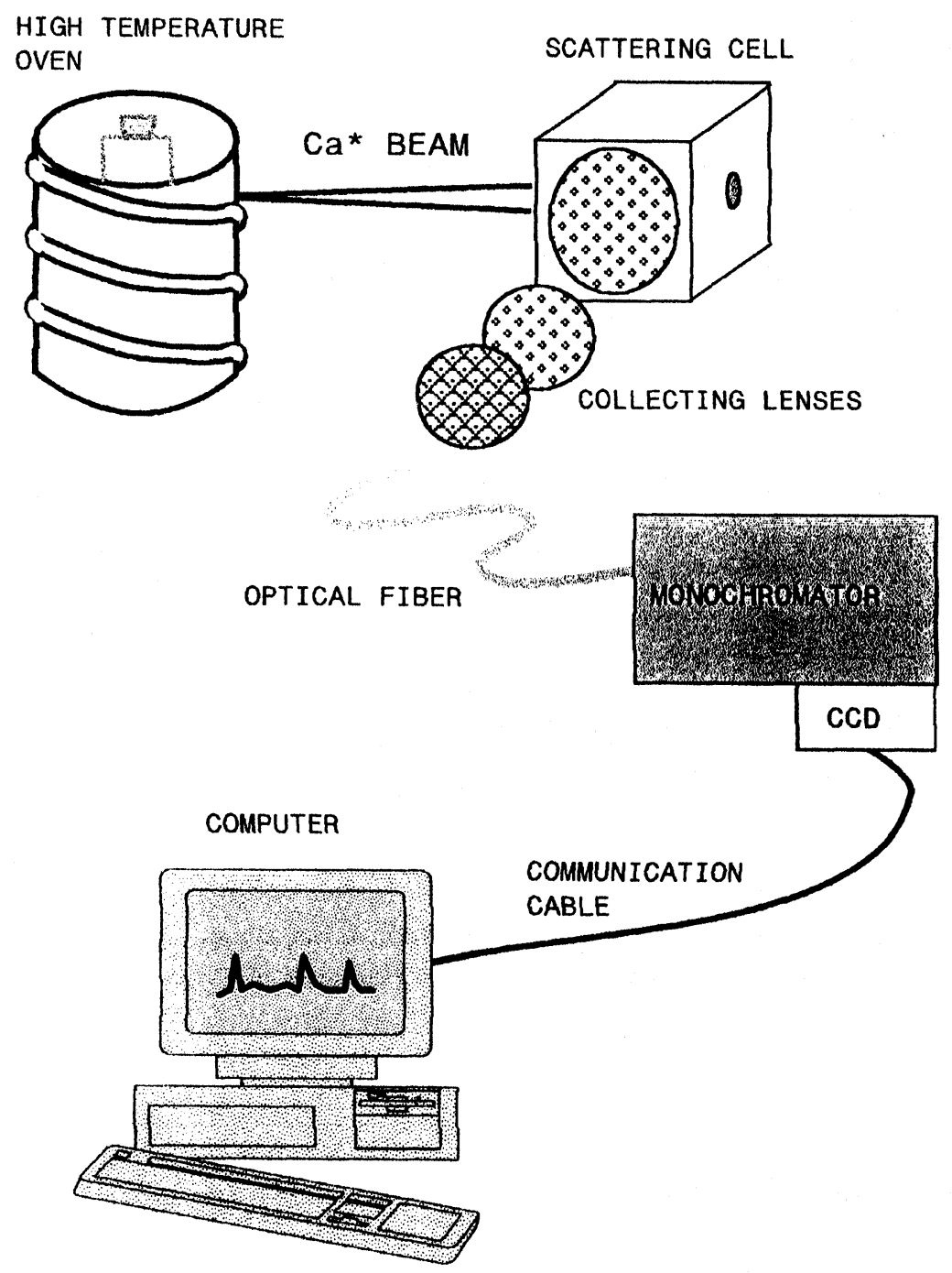

FIGURE 5 Schematic view of the beam-gas set-up used to study the stereodynamics of elementary reactions. See Ref. 16 for more details.

reaction. See for example Ref. 16 for a study of the stereodynamics of the $\mathrm{Ca}^{*}+\mathrm{HBr} \rightarrow \mathrm{CaBr}^{*}+\mathrm{H}$ reaction based on measurements of the polarization of the chemiluminescence. 


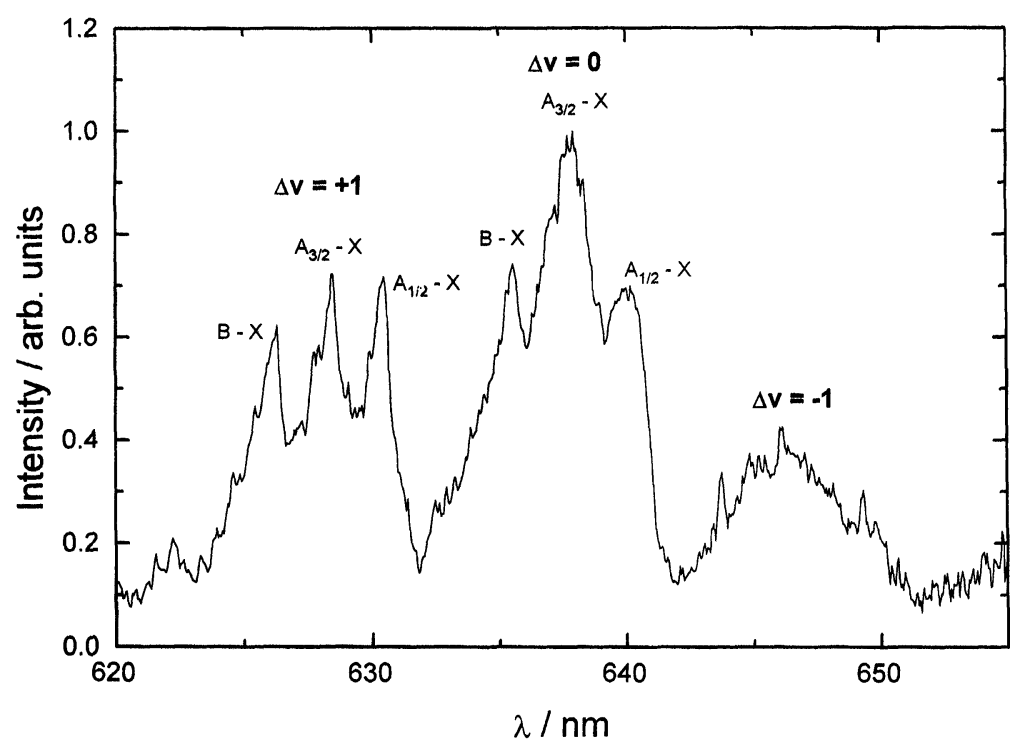

FIGURE 6 Low-resolution spectrum of the $\mathrm{CaI}(\mathrm{A}, \mathrm{B})$ formed in the $\mathrm{Ca}^{*}\left({ }^{3} \mathrm{P}_{J},{ }^{1} \mathrm{D}_{2}\right)$ $+\mathrm{CH}_{3} \mathrm{I} \rightarrow \mathrm{CaI}^{*}(\mathrm{~A}, \mathrm{~B})+\mathrm{CH}_{3}$ reaction. Notice the ${ }^{2} \Pi_{3 / 2} \rightarrow{ }^{2} \Pi_{1 / 2}$ splitting as well the presence of the $\mathrm{CaI}\left(\mathrm{B}^{2} \Sigma^{+}\right)$state.

In a series of experiments carried out under beam-gas conditions both chemiluminescence spectra and absolute values of the reaction cross-sections were measured for the reaction system

$$
\mathrm{Ca}\left({ }^{1} \mathrm{D}_{2},{ }^{3} \mathrm{P}_{J}\right)+\mathrm{RX} \rightarrow \mathrm{CaX}+\mathrm{R}
$$

in which $\mathrm{R}=\mathrm{CH}_{3}, \mathrm{C}_{2} \mathrm{H}_{5}$ and $n-\mathrm{C}_{3} \mathrm{H}_{7}$ and $\mathrm{X}=\mathrm{I}, \mathrm{OH}$. One of the basic objectives in undertaking this systematic study was the study of the radical effect in these reactive collisions. Another, perhaps, more interesting objective was to measure the reactivity in absolute values. The reader is addressed to Ref. 1 for further details about the methods to estimate $\sigma_{R}$ in absolute values, e.g. $\AA^{2}$. For a better illustration Table I lists $\sigma_{R}$ values for several reactions mostly measured in our laboratory.

Figure 7 displays the evolution of the total reaction cross-section, normalized to the methyl reaction, as a function of the size of the radical group. For a better illustration data from the well known 
TABLE I Absolute values of $\sigma_{R}$ obtained for several chemiluminescent reactions*

\begin{tabular}{ll}
\hline Reaction & $\sigma_{R} / \AA^{2}$ \\
\hline $\mathrm{Ca}\left({ }^{3} \mathrm{P}\right)+\mathrm{SF}_{6} \rightarrow \mathrm{CaF}(\mathrm{A})+\mathrm{SF}_{5}$ & 0.54 \\
$\mathrm{Ca}\left({ }^{3} \mathrm{P}\right)+\mathrm{SF}_{6} \rightarrow \mathrm{CaF}(\mathrm{B})+\mathrm{SF}_{5}$ & 0.12 \\
$\mathrm{Ca}\left({ }^{1} \mathrm{D}\right)+\mathrm{SF}_{6} \rightarrow \mathrm{CaF}(\mathrm{A})+\mathrm{SF}_{5}$ & 0.59 \\
$\mathrm{Ca}\left({ }^{1} \mathrm{D}\right)+\mathrm{SF}_{6} \rightarrow \mathrm{CaF}(\mathrm{B})+\mathrm{SF}_{5}$ & 0.04 \\
$\mathrm{Ca}\left({ }^{3} \mathrm{P}\right)+\mathrm{Cl}_{4} \mathrm{C} \rightarrow \mathrm{CaCl}+\mathrm{Cl}_{3} \mathrm{C}$ & 0.25 \\
$\mathrm{Ca}\left({ }^{1} \mathrm{D}\right)+\mathrm{Cl}_{4} \mathrm{C} \rightarrow \mathrm{CaCl}+\mathrm{Cl}_{3} \mathrm{C}$ & 1.77 \\
$\mathrm{Ca}\left({ }^{3} \mathrm{P}\right)+\mathrm{N}_{2} \mathrm{O} \rightarrow \mathrm{CaO}+\mathrm{N}_{2}$ & 4.80 \\
$\mathrm{Ca}\left({ }^{1} \mathrm{D}\right)+\mathrm{N}_{2} \mathrm{O} \rightarrow \mathrm{CaO}+\mathrm{N}_{2}$ & 3.60 \\
$\mathrm{Ca}\left({ }^{1} \mathrm{D}_{2}\right)+\mathrm{HCl} \rightarrow \mathrm{CaCl}(\mathrm{A})+\mathrm{H}$ & $1.04 \pm 0.17$ \\
$\mathrm{Ca}\left({ }^{1} \mathrm{D}_{2}\right)+\mathrm{HCl} \rightarrow \mathrm{CaCl}(\mathrm{B})+\mathrm{H}$ & $0.14 \pm 0.02$ \\
$\mathrm{Ca}\left({ }^{1} \mathrm{D}_{2}\right)+\mathrm{HBr} \rightarrow \mathrm{CaBr}(\mathrm{A})+\mathrm{H}$ & $2.2 \pm 0.9$ \\
$\left.\mathrm{Ca}\left({ }^{1} \mathrm{D}_{2}\right)+\mathrm{HBr}_{\mathrm{HBB}} \mathrm{CaB}\right)+\mathrm{H}$ & $0.52 \pm 0.24$ \\
$\mathrm{Ca}\left({ }^{1} \mathrm{D}_{2}\right)+\mathrm{CH}_{3} \mathrm{OH} \rightarrow \mathrm{CaOH}(\mathrm{A})+\mathrm{CH}_{3}$ & $0.011 \pm 0.005$ \\
$\mathrm{Ca}\left({ }^{1} \mathrm{D}_{2}\right)+\mathrm{C}_{2} \mathrm{H}_{5} \mathrm{OH} \rightarrow \mathrm{CaOH}(\mathrm{A})+\mathrm{C}_{2} \mathrm{H}_{5}$ & $0.007 \pm 0.004$ \\
$\mathrm{Ca}\left({ }^{1} \mathrm{D}_{2}\right)+\mathrm{CH}_{3} \mathrm{OH} \rightarrow \mathrm{CaOH}(\mathrm{B})+\mathrm{CH}_{3}$ & $0.003 \pm 0.001$ \\
$\mathrm{Ca}\left({ }^{1} \mathrm{D}_{2}\right)+\mathrm{C}_{2} \mathrm{H}_{5} \mathrm{OH} \rightarrow \mathrm{CaOH}(\mathrm{B})+\mathrm{C}_{2} \mathrm{H}_{5}$ & $0.001 \pm 0.0006$ \\
$\mathrm{Ca}\left({ }^{3} \mathrm{P}_{J}\right)+\mathrm{CH}_{3} \mathrm{OH} \rightarrow \mathrm{CaOH}(\mathrm{A})+\mathrm{CH}_{3}$ & $0.002 \pm 0.001$ \\
$\mathrm{Ca}\left({ }^{3} \mathrm{P}_{J}\right)+\mathrm{CH}_{3} \mathrm{OH}+\mathrm{CaOH}(\mathrm{B})+\mathrm{CH}_{3}$ & $0.0004 \pm 0.002$ \\
\hline
\end{tabular}

*Adapted from Ref. 10.

$\mathrm{K}+\mathrm{IR} \rightarrow \mathrm{KI}+\mathrm{R}\left(\mathrm{R}=\mathrm{CH}_{3}, \mathrm{C}_{2} \mathrm{H}_{5}, n-\mathrm{C}_{3} \mathrm{H}_{7}\right)$ reaction family, also measured in our laboratory, is enclosed. After inspection of Figure $7 \mathrm{a}$ negative dependence on the $\sigma_{R}$ value is clearly noticeable, as the radical group increases. This body of data together with additional results from our and other laboratories, allowed us to suggest two distinct mechanisms for the $\mathrm{Ca}\left({ }^{1} \mathrm{D}_{2}\right)$ and $\mathrm{Ca}\left({ }^{3} \mathrm{P}_{J}\right)$ attack to the alkyliodide target. Briefly, whereas the $\mathrm{Ca}\left({ }^{3} \mathrm{P}_{J}\right)$ reaction proceeds via a collinear attact to the $\mathrm{I}-\mathrm{C}$ bond, the $\mathrm{Ca}\left({ }^{1} \mathrm{D}_{2}\right)$ was suggested to react via an insertion into the same I-C bond. These two suggested mechanisms are pictorially depicted in Figure 8. The reader is addressed to Ref. 13 for further details.

\section{LASER-INDUCED BEAM SURFACE REACTIONS [17-20]}

A new beam-surface, ultrahigh-vacuum apparatus has been constructed in our laboratory. Its main details are schematically shown in 


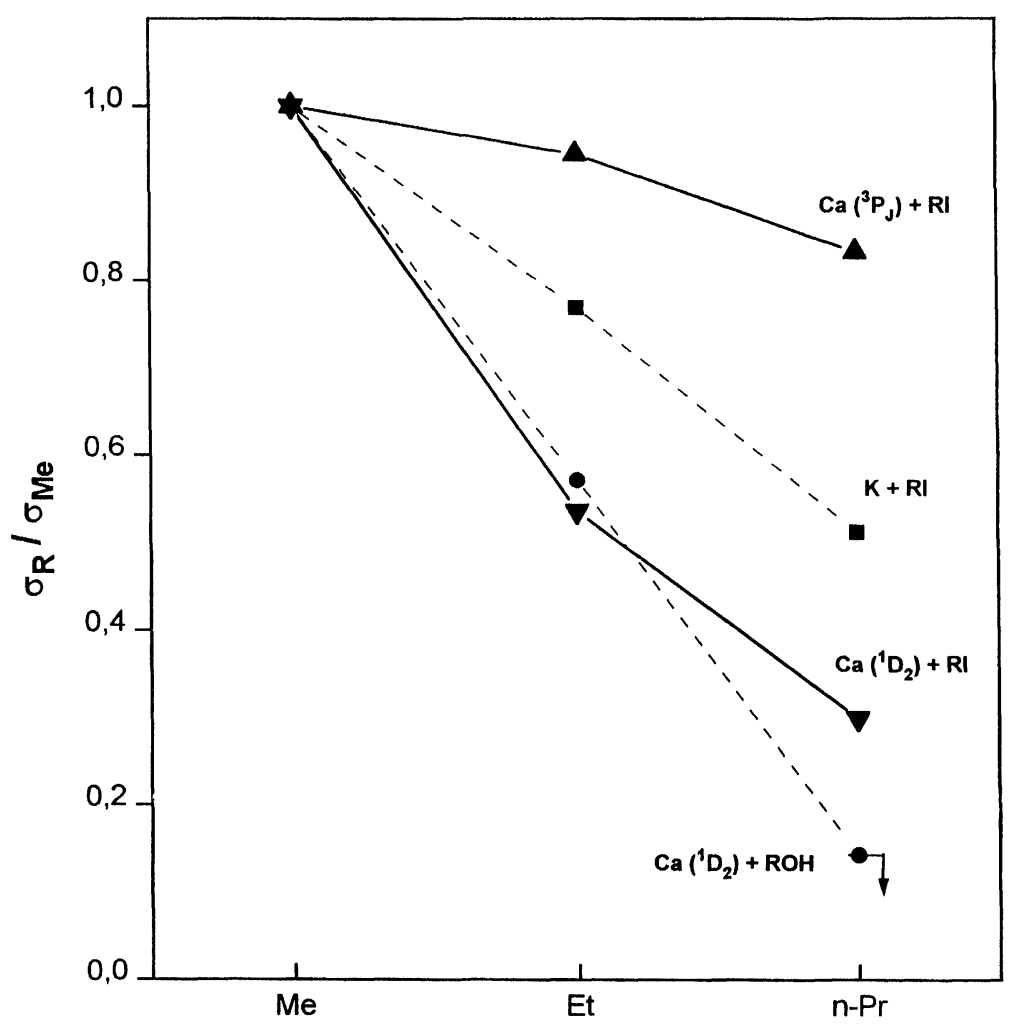

RADICAL

FIGURE 7 Normalized reaction cross-section data as a function of the radical size for several chemiluminiscent reactions as indicated. All the data is normalized to 1 for the methyl group. Adapted from Refs. 9 and 13.

Figure 9. In this new set-up, a molecular beam of $\mathrm{SF}_{6}$ is directed onto a $\mathrm{Ba}$ metal sample. A tunable infrared $\mathrm{CO}_{2}$ laser is focussed on the point where the molecular beam impinges on the barium surface. The typical experiment essentially consists of measuring either the positive or negative ion yield as a function of the laser wavelength. Our basic motivation is to look for beam-surface ionization processes induced by laser radiation. If we find this, we then look for thermally or vibrationally enhanced effects. These studies are important not only from a 

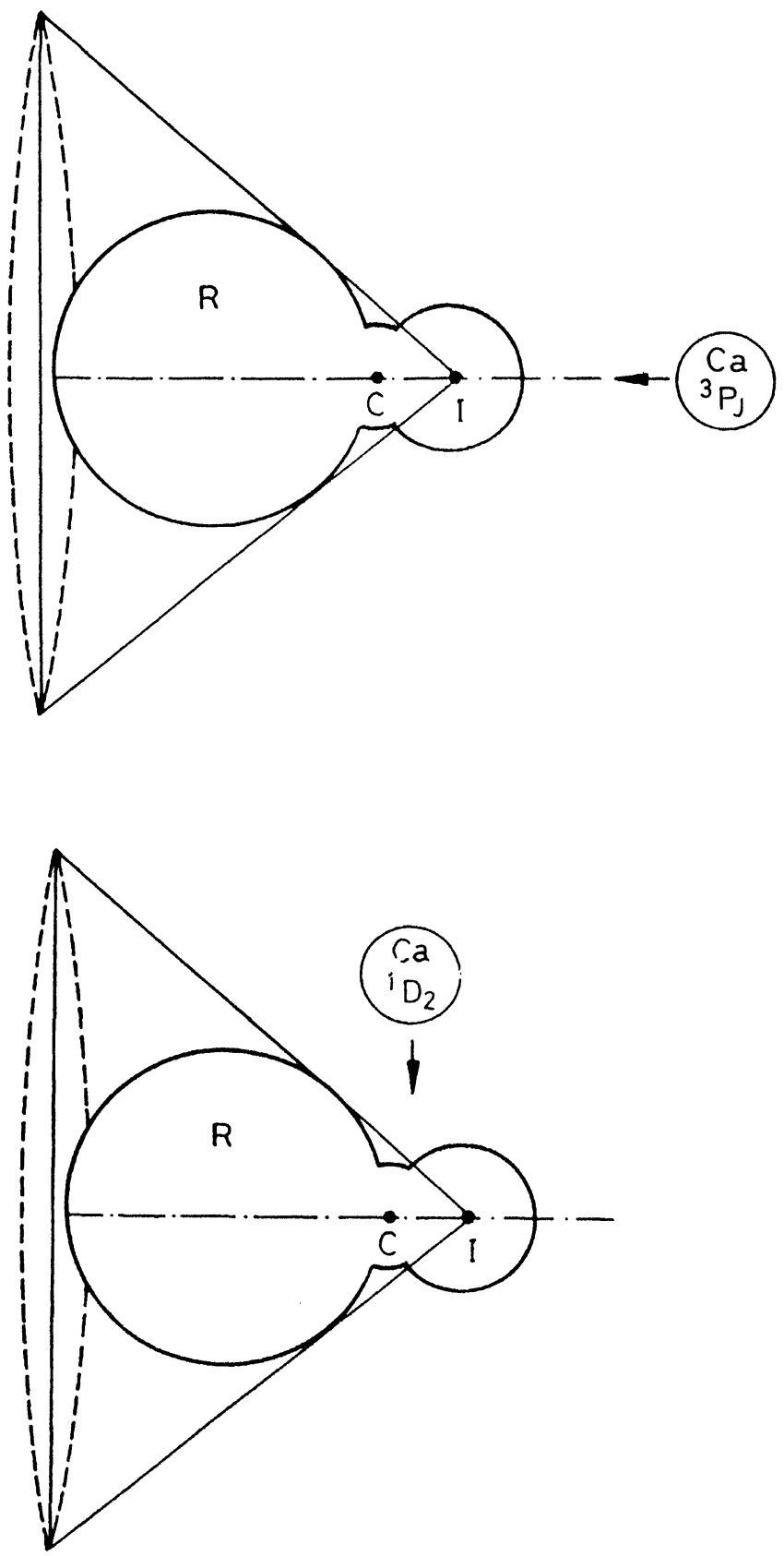

FIGURE 8 Pictorial description of the abstraction (top) and insetion mechanism (bottom) for the $\mathrm{Ca}\left({ }^{3} \mathrm{P}_{J}\right), \mathrm{Ca}\left({ }^{1} \mathrm{D}_{2}\right)$ attack to the RI target. 


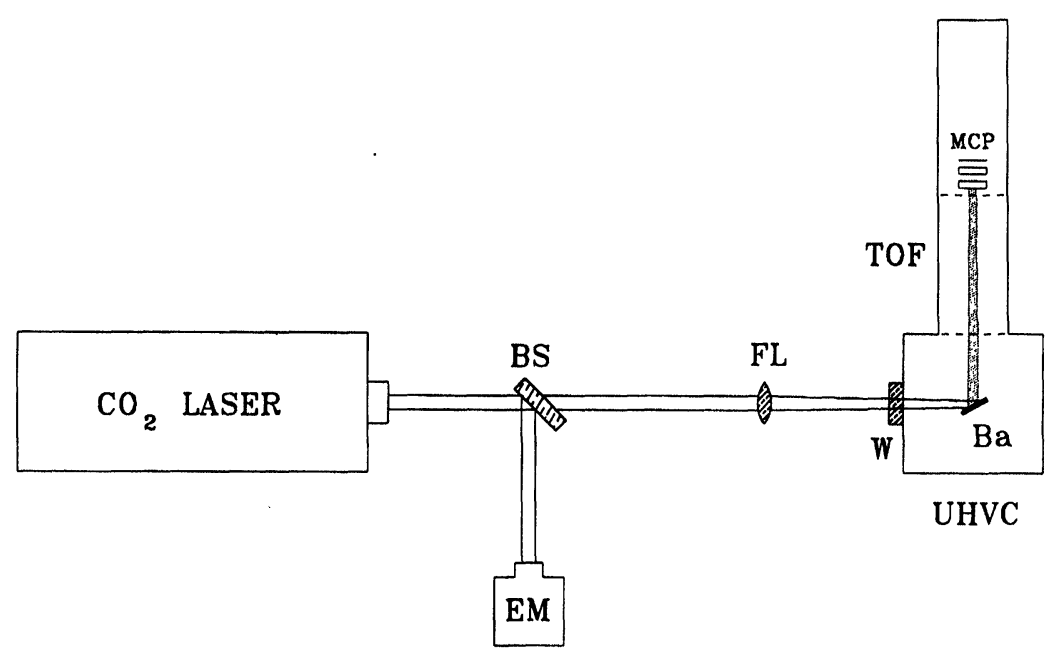

FIGURE 9 Simple layout of our laser-beam surface apparatus. A molecular beam impinges on the metal surface at the same point as the $\mathrm{CO}_{2}$ laser. The ionization spectrum is obtained as the laser wavelength is scanned. BS: Beam splitter. EM: Energy meter. FL: Focal Lens. W: KBr window. UHVC: Ultra-high vacuum chamber. Ba: Barium. TOF: Time of flight tube. MCP: Microchannel plate detectors.

fundamental viewpoint, as they may be important in laser catalysis or laser analytical chemistry of polyatomic adsorbed molecules. The reader is addressed to the Faraday Discussion on Dynamics at the Gas Solid Surface (Faraday Discussion no. 96, 1993) for a recent account of the research activity in this field.

Figure 10 displays laser ionization time-of-flight (T.O.F.) spectra obtained using the above mentioned technique. As indicated, the solid line represents the negative ion yield (mostly $\mathrm{SF}^{-}{ }_{6}$ ) obtained with laser excitation at the resonant frequency of $10.6 \mu \mathrm{m}$. The broken line shows the same spectrum but using the non-resonant line at $9.6 \mu \mathrm{m}$. Note the significant signal enhancement at resonant excitation of the vibrational mode (i.e. $10.6 \mu \mathrm{m}$ ) even though the laser Energy Fluence is smaller than that of the $9.6 \mu \mathrm{m}$ line. See Figure and References 17-20 for further details. The vibrational enhancement of the negative ion yield is now being studied with higher resolution under time-offlight mass spectrometric conditions. 


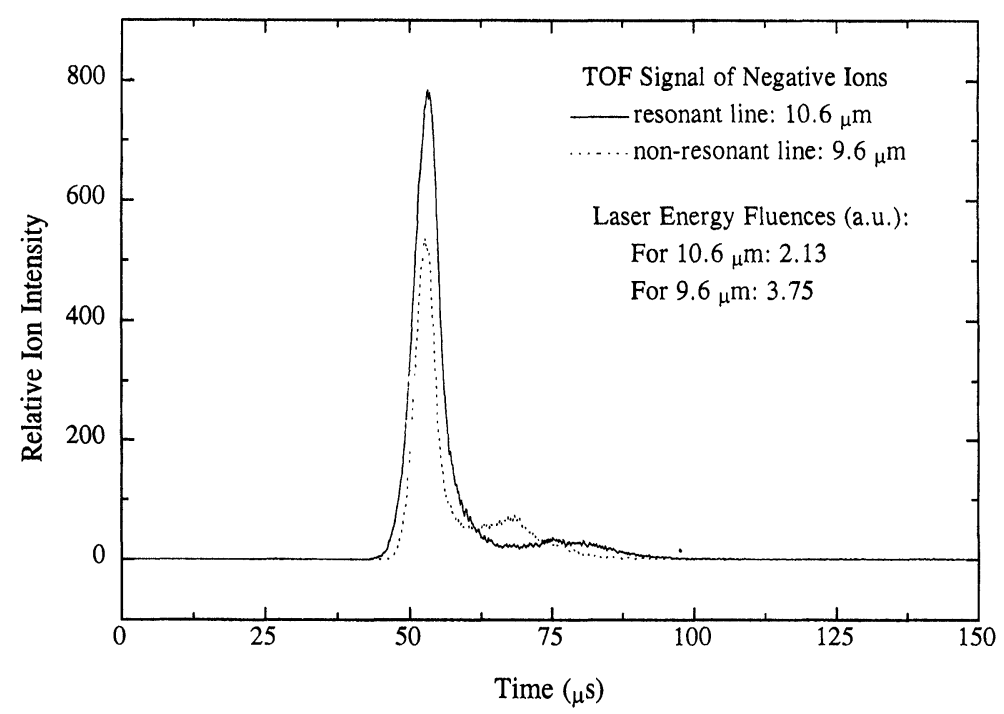

FIGURE 10 Time-of-flight spectra obtained by laser ionization of $\mathrm{SF}_{6} /$ Barium interface. Solid line represents the negative ion yield (mostly $\left.\mathrm{SF}_{6}\right)$ obtained with laser excitation at the resonant frequency of $10.6 \mu \mathrm{m}$. Broken line shows the same spectrum but using the non-resonant line at $9.6 \mu \mathrm{m}$. The important enhancement at the resonant excitation, even carried out at lower laser energy fluence, should be noticed.

\section{LASER ANALYTICAL CHEMISTRY [21-22]}

In this laboratory two different set-ups are now operating giving the first results. The first of these is a conventional laser ablation spectroscopy set-up. A dye laser, pumped by the frequency-doubled $532 \mathrm{~nm}$ output of a Q-switched Nd:YAG laser, is focussed onto the solid sample to be analyzed. The microplasma emission produced after laser ablation is collected by an optical multichannel analyzer (OMA). Novel features include the capability of changing a whole set of parameters to optimize the data analysis. These are laser pulse energy, wavelength and delay time from the trigger pulse until the emission recording starts. In addition, the use of an OMA allows a broad range of emission wavelengths to be monitored simultaneously. This experimental set-up already operating in our laboratory has clear advantages with respect to more conventional methods. Some of these advantages are: faster analysis, high resolution and versatility. Preliminary results on $\mathrm{Al}$ samples have proved to be useful in the analysis of trace elements 
such as $\mathrm{Fe}, \mathrm{Cu}, \mathrm{Mn}, \mathrm{Pb}, \mathrm{Ti}$, etc, down to the low ppm range. Figure 11 shows a typical spectrum of the simultaneous detection of $\mathrm{Mg}, \mathrm{Mn}, \mathrm{Fe}$ and $\mathrm{Pb}$ in $\mathrm{Al}$ samples using the above mentioned laser-breakdown spectroscopy. Using optimal conditions we were able to determine minor components in the $0.01 \%$ concentration range and so, quantitative analysis of metallic samples was accomplished with this laser analytical setup. Further details can be found in Refs. 21 and 22.

The same laser is now being used in a new two-photon technique dedicated to environmental analysis of (solid) organic pollutants. Essentially the technique consists of using a first low energy photon to softly desorb the organic compounds avoiding (molecular) photofragmentation. This vapour is then probed using a nitrogen laser, optimizing the time delay between both lasers. The laser induced fluorescence is collected and led to an Optical Multichannel Analyzer (OMA) by means of an optical fiber. The experimental arrangement is shown in Figure 12. Some preliminary desorption results for anthracene are shown in Figure 13. It is hoped that this technique will provide a convenient method for analysis of fluorescent pollutants in the environment.

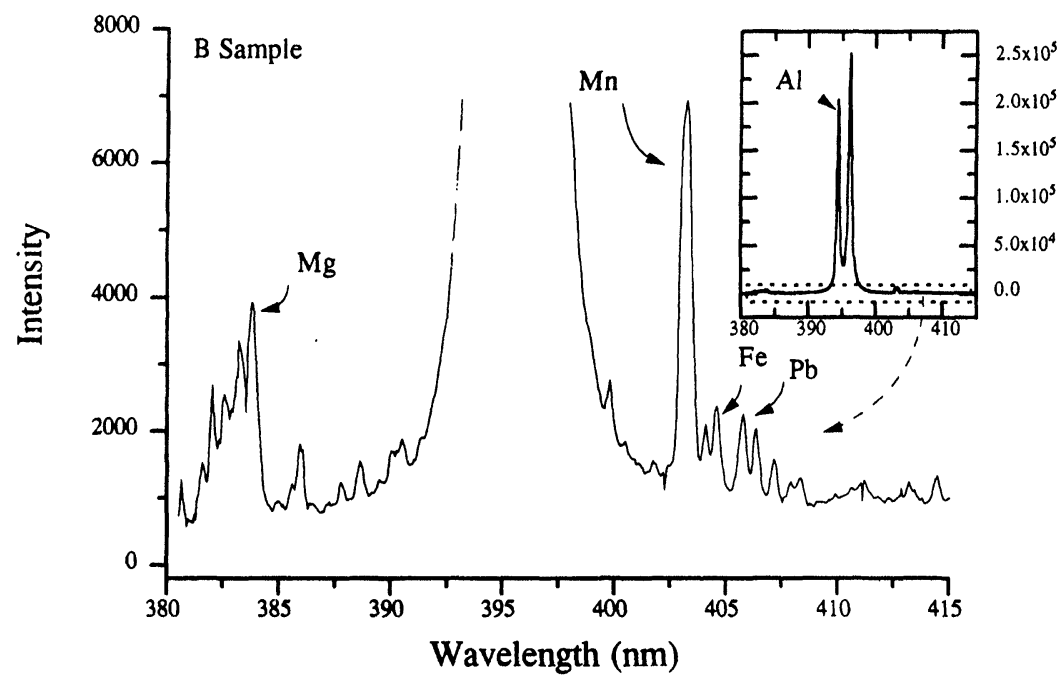

FIGURE 11 Emission spectrum of trace elements in an Al-sample produced by laser ablation spectroscopy. Notice the $\mathrm{Mg}, \mathrm{Mn}, \mathrm{Fe}$ and $\mathrm{Pb}$ peaks. See references 21 and 22 for further information. 


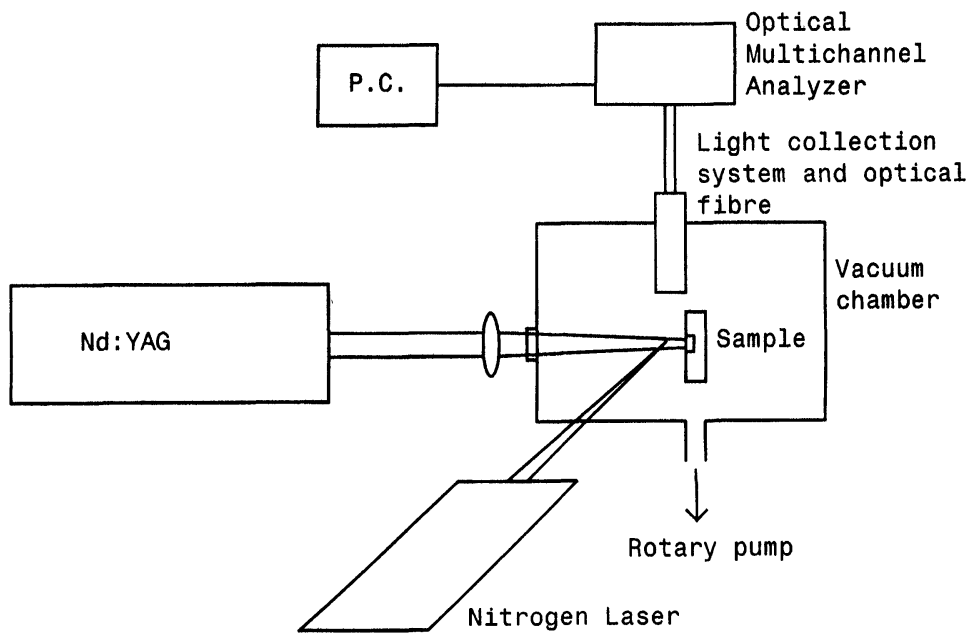

FIGURE 12 Schematic view of the laser desorption experiment.

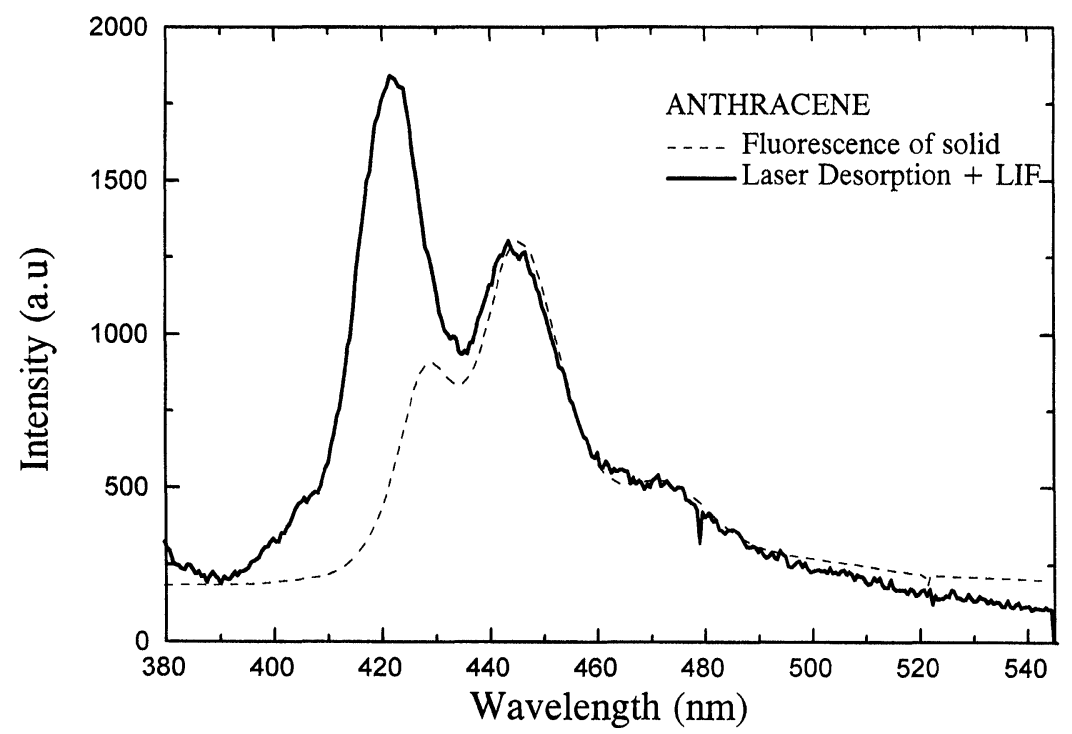

FIGURE 13 Laser induced fluorescence spectrum of Anthracene desorbed by a pulse from a Nd: YAG laser. 


\section{LASER INITIATED REACTIONS STUDIED BY CHEMILUMINESCENCE AND LASER-INDUCED FLUORESCENCE (LIF) [23]}

The study of the fundamental reactions of the refractive materials is difficult due to the technical problems associated with producing such materials in the gas phase. In this experiment the relatively new technique of laser ablation is applied for this purpose. The basic idea is to use a short intense laser pulse to vaporize the sample in a reactive atmosphere. The reaction of this sample can then be followed by chemiluminescence, or in the case where there is no chemiluminescence, by laser induced fluorescence.

As an example of such a possibility we present some results obtained for the reaction $\mathrm{Al}+\mathrm{O}_{2} \rightarrow$ products. The aluminum atoms are ablated into the oxygen atmosphere and rapidly oxidized to AlO. With high oxygen concentrations a sequence of reactions is possible which produces $\mathrm{AlO}$ in an excited state allowing chemiluminescence to be observed (see Fig. 14). In order to further study the reaction of this excited $\mathrm{AlO}$ with oxygen, we pumped this molecule with an $\mathrm{Ar}^{+}$c.w. laser and measured the fluorescence at different mixtures of $\mathrm{O}_{2}$ and $\mathrm{N}_{2}$, keeping the total pressure at a constant value. This fluorescence is shown in Figure 15. The c.w. laser excites high $J$ rotational transitions. Low $J$ transitions are observed which are not pumped by the excitation laser, indicating that there is rotational relaxation. Evidence for the excited state reaction can be inferred from the decrease in emission from low $J$ levels with an increase in oxygen pressure. This observation can only be satisfactorily explained by invoking an excited state reaction which removes the $\mathrm{AlO}$ before full rotational relaxation can occur. Analysis of this body of data has allowed us to derive rate constants for excited $\mathrm{AlO}$ reaction with oxygen (See Ref. 23) from different vibrational states.

\section{SPECTROSCOPY AND REACTIVITY OF VAN DER WAALS MOLECULES [24-27]}

This new research project is concentrated on the experimental investigation of the transition region of metal-molecule reactions. The reagents are condensed within a weakly bound species and the reaction is 


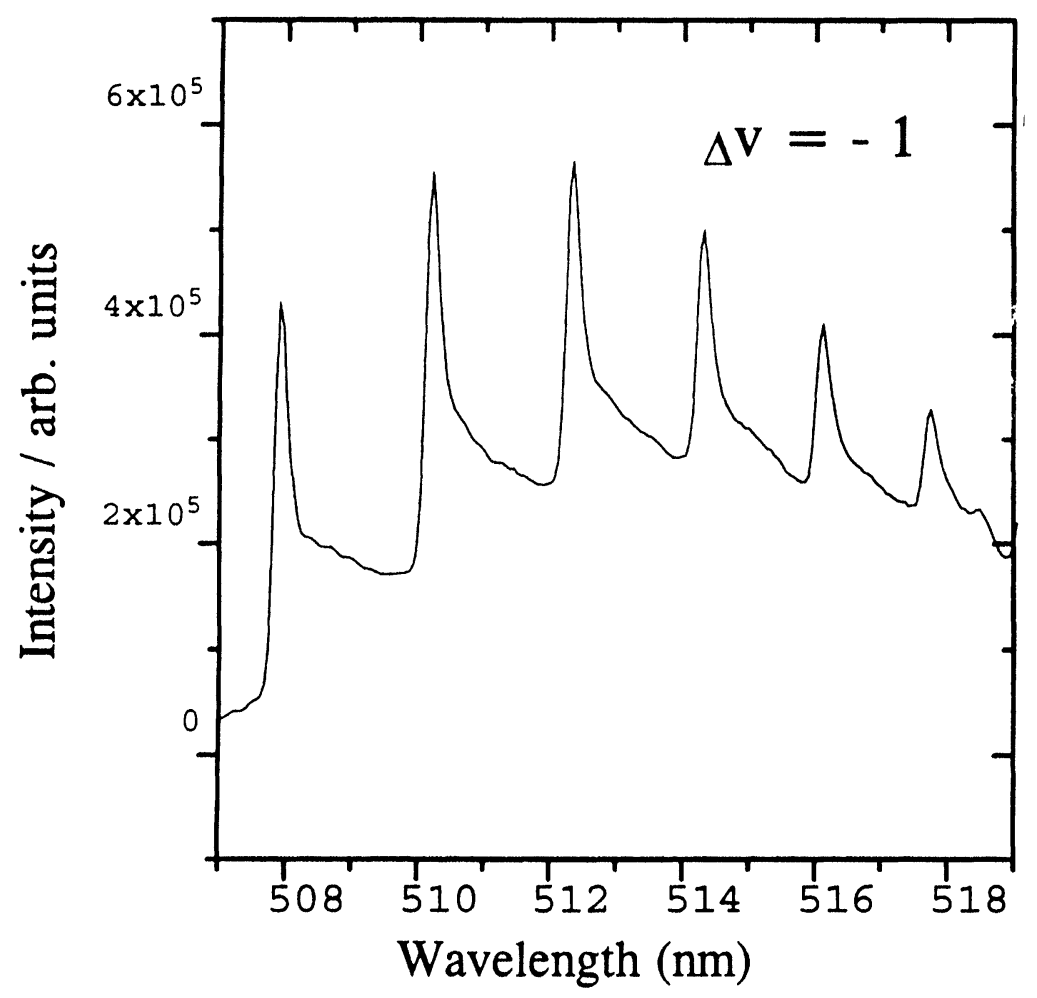

FIGURE 14 Chemiluminescence spectrum corresponding to the AlO $(\mathrm{B} \rightarrow \mathrm{X})$ transition obtained when aluminium atoms are ablated into an oxygen atmosphere.

initiated by optical means. The experimental setup incorporates previous beam and laser spectroscopic developments described elsewhere [24-26]. The structure and reactivity of van der Waals molecules is a very active field of research. The reader is addressed to Ref. 27 and references cited therein for detailed information about this subject.

van der Waals (vdW) molecules are prepared and analysed spectroscopically in the experimental arrangement shown schematically in Figure 16. The focalized fundamental frequency of a pulsed Nd-YAG laser running at $10 \mathrm{~Hz}$ is used to vaporize atoms from a metal disc. The vapor of the metal is carried by a mixture of helium gas and a solvent. van der Waals molecules between the metal and the solvent are formed as a result of the supersonic expansion that takes place in 


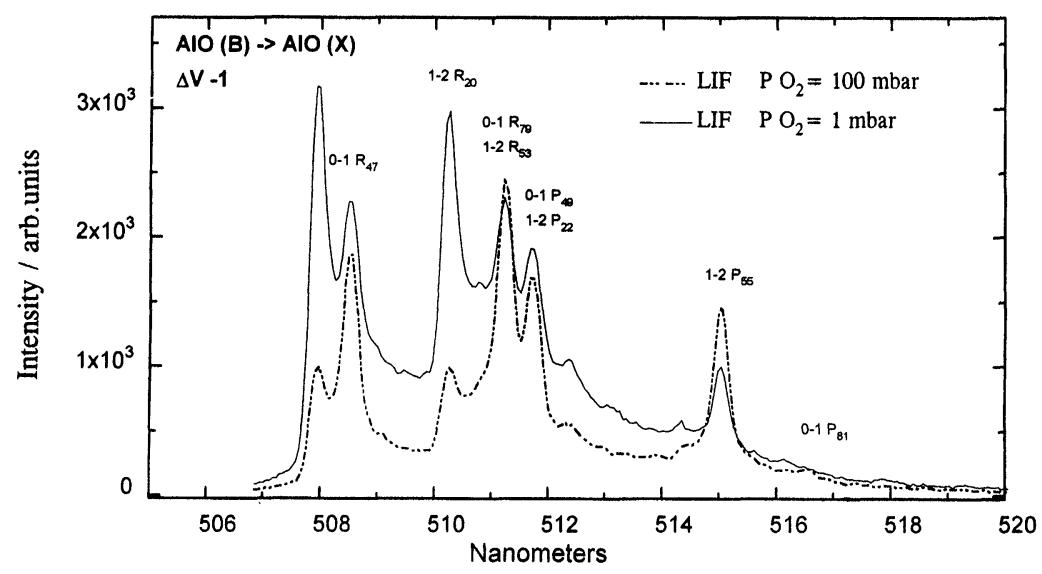

FIGURE 15 Laser induced fluorescence spectrum of AlO for varying partial pressures of $\mathrm{O}_{2}$. The wavelength of the excitation laser is $488.0 \mathrm{~nm}$, which pumps high rotation levels. The presence of emission from low $\mathrm{J}$ levels is due to rotational relaxation.

the first vacuum chamber. The supersonic jet phases through a skimmer and the molecular beam produced can then be investigated in different ways. First, in previous experiments, a quadrupole mass spectrometer was used for detection. With this scheme, time of flight spectra for various masses, demonstrating unambiguously the presence of van der Waals molecules for the $\mathrm{Na}$ expanded with $\mathrm{CO}_{2}$ beams, have been reported [26]. Second, the molecular beam can also be probed inside the extraction region of a time of flight mass spectrometer equipped with microchannel plate detection. In this arrangement, the output of a Nd-YAG pumped dye laser is used to excite/ionize the species of interest. The three events, vaporization pulse, gas pulse and excitation/ionization pulse are synchronized using a home-made pulse generator. With this setup it is possible to measure mass spectra as a function of the flight time and to perform one or two-color twophoton REMPI (resonance enhanced multiphoton ionization) scans monitoring a selected mass. Photodepletion experiments can also be carried out (see below).

Figure 17 shows the mass spectrum obtained from the ionization with the 4th harmonic of a Nd-YAG laser a molecular beam of barium, $\mathrm{CH}_{3} \mathrm{Cl}$ and helium optimized for the $\mathrm{Ba}\left(\mathrm{CH}_{3} \mathrm{Cl}\right)_{2}$ vdW molecule. The five most abundant isotopes of barium and their van der 

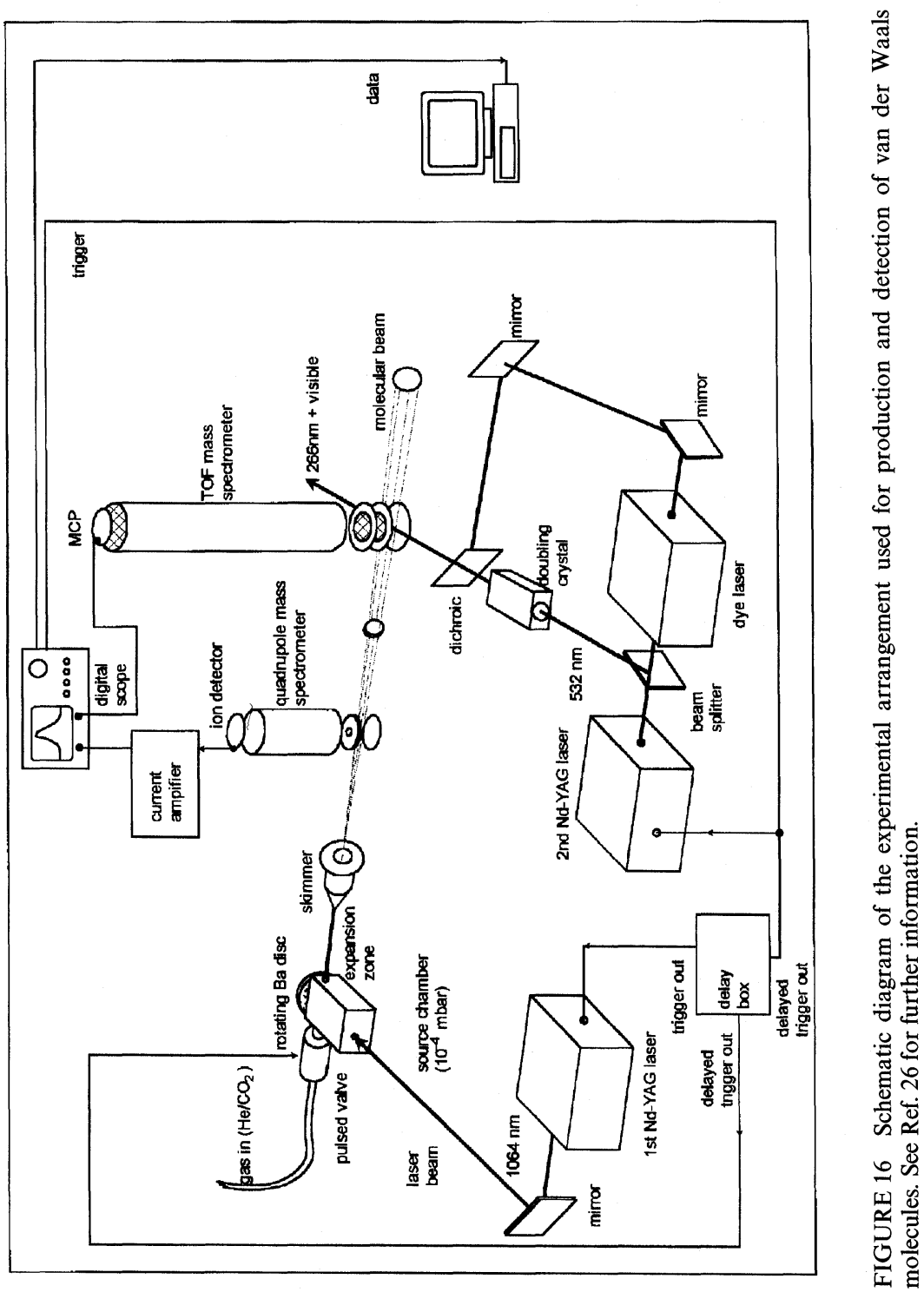


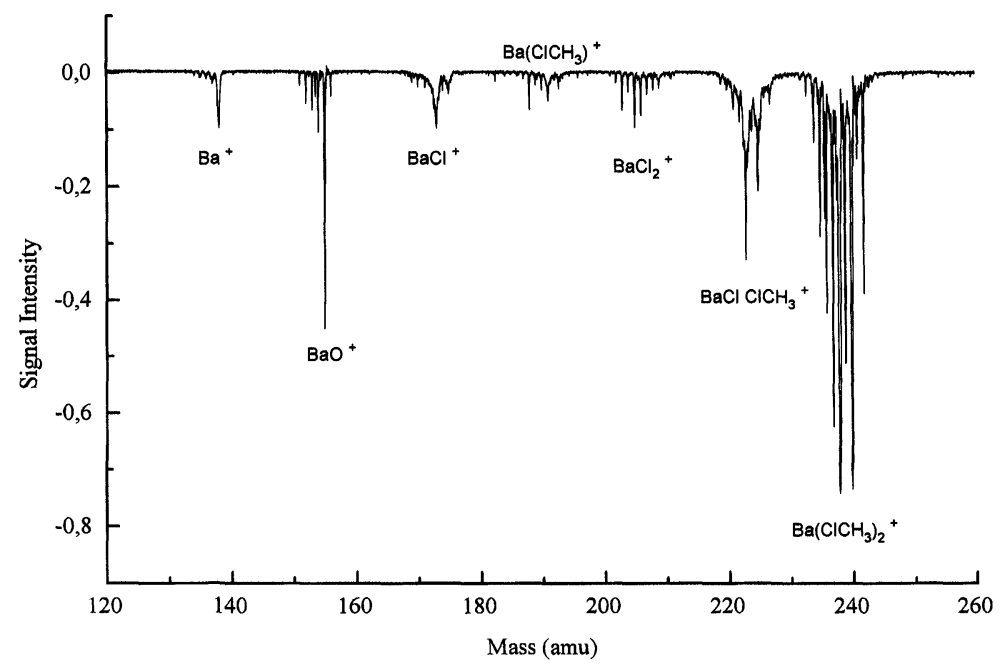

FIGURE 17 Time of flight mass spectrum of a beam of $\mathrm{Ba},\left(\mathrm{CH}_{3} \mathrm{Cl}\right)$ and helium obtained after ionization with the 4 th harmonic of a Nd-YAG laser.

Waals complexes with $\mathrm{CH}_{3} \mathrm{Cl}$ are detected. $\mathrm{BaO}^{+}, \mathrm{BaCl}^{+}$and $\mathrm{BaCl}_{2}{ }^{+}$ are also present in the beam. The barium oxide is coming from the oxidized metal present in the disc and the $\mathrm{BaCl}$ and $\mathrm{BaCl}_{2}$ are likely the reaction products of some of the van der Waals molecules after laser excitation.

A second experiment was also carried out to study the photodepletion of $\mathrm{vdW}$ molecules as a result of the chemical reaction photoinitiated by laser excitation (Fig. 18). In this case, the second harmonic output of the Nd-YAG laser is split into two beams, one is used to pump the dye laser and the other is doubled to give $266 \mathrm{~nm}$. Both beams are optically synchronized to make sure that the visible light arrives a few nanoseconds earlier to the sample. When the dye laser is tuned to one of the electronic transitions of the van der Waals complex the excited state may react leading to different products. Consequently, the $\mathrm{Ba}\left(\mathrm{CH}_{3} \mathrm{Cl}\right)_{n}$ concentration decreases while new species are ionized and detected. This is the case shown in Figure 18. The upper trace corresponds to the mass spectrum recorded when the ultraviolet radiation is interacting with the beam and the dye laser is blocked. In this case, the $\mathrm{Ba}\left(\mathrm{CH}_{3} \mathrm{Cl}\right)_{2}^{+}$signal is the most intense. When the dye 


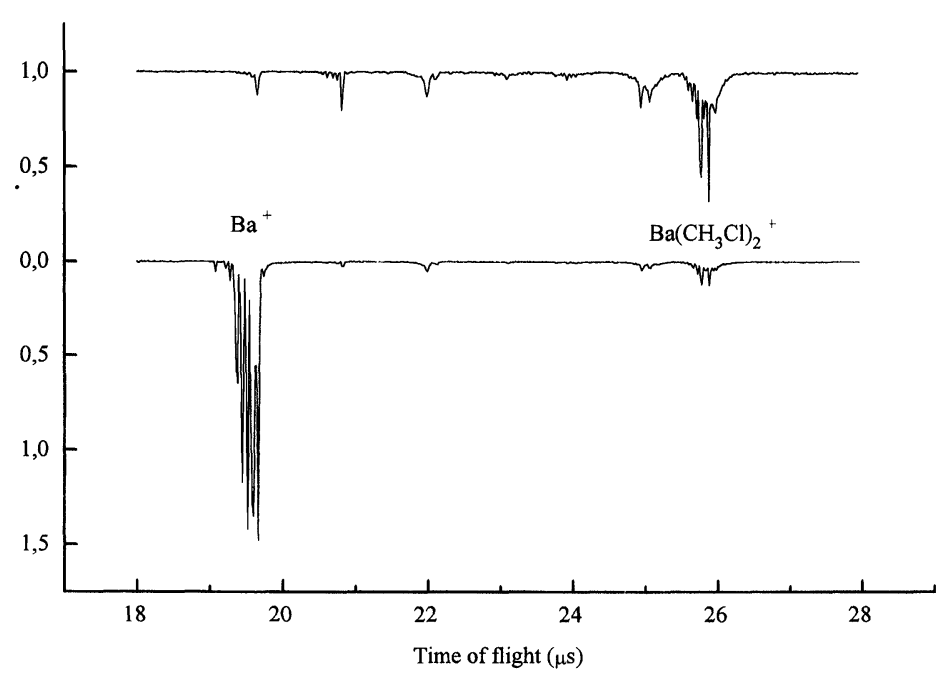

FIGURE 18 Time of flight mass spectra of a beam of $\mathrm{Ba}, \mathrm{CH}_{3} \mathrm{Cl}$ and helium obtained when excitation is produced with the 4th harmonic of a Nd-YAG laser (upper trace) and when a dye laser tuned to $553.5 \mathrm{~nm}$ is used together with the $266 \mathrm{~nm}$ beam (lower trace). The photodepletion of the van der Waals complex is clearly noticed. See text for details.

laser, tuned to the barium atomic transition $\left({ }^{1} \mathrm{~S}-{ }^{1} \mathrm{P}\right) \lambda=553.3 \mathrm{~nm}$, enters the detection chamber a decrease in intensity of the $\mathrm{Ba}\left(\mathrm{CH}_{3} \mathrm{Cl}\right)_{2}^{+}$is clearly observed while the $\mathrm{BaCl}^{+}$and $\mathrm{Ba}^{+}$increase (lower trace). The $\mathrm{Ba}$ ion signal increase is attributed to the resonantly enhanced twocolor two-photon ionization whereas the $\mathrm{BaCl}^{+}$is probably due to the ionization of the $\mathrm{BaCl}$ produced from the photoinitiated reaction within the van der Waals molecule.

Work is now in progress to measure photodepletion spectra of van der Waals complexes in order to get insight into the transition state spectroscopy. In this case, the dye laser will be scanned over a wide range of frequencies while the $266 \mathrm{~nm}$ beam is kept for ionization. By varying the dye laser frequency we can access the reactive potential energy surface in various configurations and this will give us information about the reaction dynamics as a function of the transition state configuration.

Also, the photoionization threshold of these molecules can be measured. In this experiment a tunable laser is used to photoionize the van der Waals molecules. Starting at a wavelength where ion signal is observed, the wavelength is increased until the point is 
reached at which the signal disappears. At this point the photons no longer have sufficient energy to ionize the van der Waals molecules. This wavelength represents the adiabatic ionization potential, whose measurement can provide information about the structure of both the neutral and ionized van der Waals molecule.

\section{Acknowledgement}

We would like to thank the current support to our research activity by the Spanish DGICYT (grant no. PB91-357) and the Ramón Areces Foundation. We would like to thank to Dr. Morley for his assistance in preparing this manuscript and his collaboration in the work described in Section 4.

\section{References}

[1] Gonzalez Ureña, A. and Vetter, R. (1993). “The measurement of absolute reactive cross-section", Comments on Atomic and Molecular Physics, 29(2), 97.

[2] Garay, M., Menendez, M., Verdasco, E., Castaño, J. and Gonzalez Ureña, A. (1993). "Product Polarization in the $\mathrm{Ca}\left({ }^{1} \mathrm{D}_{2}\right)+\mathrm{HCl} \rightarrow \mathrm{CaCl}(\mathrm{B})+\mathrm{H}$ reaction", $J$. Phys. Chem., 97, 5836.

[3] Menendez, M., Garay, M., Verdasco, E. and Gonzalez Ureña, A. (1993). "On the determination of $\mathrm{D}^{0}{ }_{0}(\mathrm{CaCl})$ from translational energy threshold measurements", J. Chem. Phys., 99, 2760.

[4] Menendez, M., Garay, M., Verdasco, E. and Gonzalez Ureña, A. (1993). "Collision Energy and Product Polarization Effects in the $\mathrm{Ca} *\left({ }^{1} \mathrm{D}_{2}\right)+\mathrm{HCl} \rightarrow \mathrm{CaCl}^{*}$ (A, B) + H Reaction", J. Chem. Soc. Faraday Trans., 89(10), 1493.

[5] Gonzalez Ureña, A. (1993). "Molecular Beam Research in the Complutense University: Progress over a decade" Anales de Quimica, 89, 562. See for example Basterrechea, F., Beitia, F., Castaño F., Sánchez-Rayo, M. N., Carl, S. and Husain, D. (1991). Bunsenges Phys. Chem., 95, 1615.

[6] Menendez, M., Garay, M., Verdasco, E. and Gonzalez Ureña, A. (1994). "Collision energy effects in the $\mathrm{Ca}\left({ }^{1} \mathrm{D}\right)+\mathrm{HCl} \rightarrow \mathrm{CaCl}(\mathrm{A})+\mathrm{H}$ reaction cross-section" Anales de Física, 90(3), 123.

[7] Menendez, M., Garay, M., Verdasco, J. E. and Gonzalez Ureña, A. (1994). "Crossed-beam (full collision) versus van der Waals (Half collision) studies. Application to the determination of the $\mathrm{D}^{0}{ }_{0}(\mathrm{Ca} . . \mathrm{HCl})$ ", J. Chem. Phys., $\mathbf{1 0 0}(1), 756$.

[8] Garay, M., Esteban, M., Verdasco, E. and Gonzalez Ureña, A. (1994). "High sensitivity in reaction cross-section measurements by optical methods: the $\mathrm{Ca}\left({ }^{1} \mathrm{D}\right)+\mathrm{C}_{2} \mathrm{H}_{5} \mathrm{OH} \rightarrow \mathrm{CaOH}^{*}+\mathrm{C}_{2} \mathrm{H}_{5}$ reaction, Faraday Transactions, 90 (24), 3732.

[9] Esteban, M., Garay, M., Garcia-Tijero, J. M., Verdasco, E. and Gonzalez Ureña, A. (1994). "Influence of the radical size on the $\mathrm{Ca}^{*}+\mathrm{ROH} \rightarrow \mathrm{CaOH}^{*}+\mathrm{R}\left(\mathrm{R}=\mathrm{CH}_{3}, \mathrm{C}_{2} \mathrm{H}_{5}\right.$ and $\left.\mathrm{C}_{3} \mathrm{H}_{7}\right)$ reaction cross-section", Chem. Phys. Letters, 230, 525.

[10] Gonzalez Ureña, A. and Vetter, R. (1995). "Reactive collision with excited atoms (Faraday Research Article), J. Chem. Soc., Faraday Trans., 91(3), 389. See also ibid: "Reaction Dynamics by optical methods", Int. Rev. Phys. Chem., 15, 375 (1996). 
[11] Gonzalez Ureña, A. and Alvariño, Y. J. M. (1994). “Estereodinámica Química I. Atomos y Moléculas Polarizados como Reactivos Químicos", Anales de Química, 25, 251.

[12] De Castro, M., Candori, R., Pirani, F., Aquilanti, V., Menendez, M., Garay, M. and Gonzalez Ureña, A. (1996). "Translational energy effects in the excited $\mathrm{Ca}\left({ }^{1} \mathrm{D}_{2}\right)+\mathrm{HCl}+\mathrm{CaCl}(\mathrm{A})+\mathrm{H}$ reaction. Experiments and a harpooning mechanism", J. Phys. Chem., 100, 7997.

[13] Garay, M., Orea, J. M. and Gonzalez Ureña, A. (1996). Chem. Phys., 207, 451.

[14] Garay, M. Tesis Doctoral. Universidad Complutense de Madrid, 1996.

[15] Verdasco, E. and Gonzalez Ureña, A. (1990). J.Chem. Phys., 93, 428.

[16] Garay, M., Esteban, M., Verdasco, E. and Gonzalez Ureña, A. (1995). Chem. Phys., 195, 235.

[17] Castaño Aspas, J., Heeg, B., Bescos, B., Zapata, V. and Gonzalez Ureña, A. (1993). "Vibrational enhancement of beam surface ionization processes", Faraday Discussion, 96, 227.

[18] Castaño Aspas, J. and Gonzalez Ureña, A. (1994). "Laser-induced negative Ionization: The $\mathrm{SF}_{6}+\mathrm{Ba}$ Surface Reaction", Laser Chemistry, 14, 201.

[19] Castaño, J., Zapata, V., Makarov, G. and Gonzalez Ureña, A. (1995). "TEA CO laser-induced $\mathrm{SF}_{6}+\mathrm{Ba}$ beam-surface ionization", J. of the Chinese Chemical Society, 42, 393.

[20] Castaño, J., Zapata, V., Makarov, G. and Gonzalez Ureña, A. (1995). "SF 6 + Ba beam-surface ionization induced by infrarred radiation", The J. Phys. Chem., 99, 13659.

[21] Bescos, B., Castaño, J. and Gonzalez Ureña, A. (1995). "Laser breakdown spectroscopy of Al-samples: Application to chemical analysis of metallic elements", Laser Chemistry, 16, 75.

[22] Bescos, B. and Gonzalez Ureña, A. (1995). "Laser chemical analysis of metallic elements in aluminium samples", Journal of Laser Applications, 7, 47.

[23] Bescos, B., Morley, G. and Gonzalez Ureña, A. (1995). "Chemiluminiscence and reactivity of aluminium monoxide ( $\mathrm{AlO})$ in the excited $\mathrm{B}\left({ }^{2} \Sigma^{+}\right)$state", Chem. Phys. Letters, 244, 407.

[24] Skowronek, S., Bañares, L. and Gonzalez Ureña, A. (1993). "High a resolution laser-beam spectroscopy using a continous tunable narrow band dye laser", Socieded Española de Optica. Especial issue on Laser Beam characterization (P. M. Mejías, ed.) 161.

[25] Skowronek, S. and Gonzalez Ureña, A. (1994). "Simple electronic device for inter modulation techniques. Aplication to high resolution laser spectroscopy in molecular beams", Measurement Science and Technology, 5, 58.

[26] Skowronek, S., Morley, G. and Gonzalez Ureña, A. (1995). Anales de Fisica, 91, 150.

[27] See for example (a) Visticot, J. P., Soep, B. and Whitham, C. J. (1988). J. Phys. Chem., 92, 4574. (b) Liu, K., Polanyi, J. C. and Yang, S. (1993). J. Chem. Phys., 98, 5431. and references cited therein. 